\title{
Factors related to high and low levels of drug adherence according to patients with type 2 diabetes
}

\author{
Sander D. Borgsteede $\cdot$ Marjan J. Westerman • \\ Irene L. Kok • Joke C. Meeuse - Theo P. G. M. de Vries • \\ Jacqueline G. Hugtenburg
}

Received: 19 January 2010/ Accepted: 13 June 2011/Published online: 7 July 2011

(C) The Author(s) 2011. This article is published with open access at Springerlink.com

\begin{abstract}
Objective Adherence to medication in patients with type 2 diabetes varies widely, yet the factors that influence adherence according to patients are not fully known. The aim of this study is to explore both factors related to high and lower levels of adherence that patients with type 2 diabetes experienced in their medication use. Setting Primary care in the Netherlands. Method Qualitative, semi-structured interviews were performed in 20 patients with type 2 diabetes. Interviews were audio-taped and transcribed verbatim. Transcripts were coded and analysed using content analysis and constant comparison. Main outcome measure experiences and opinions of patients concerning factors related to high and lower levels of adherence. Results Comparable aspects influenced drug adherence in more and less adherent patients. Four aspects that influenced adherence to medication emerged from the interviews: (1) information about the prescribed medication, (2) experience with medication and complications with use, (3) social support for medication behaviour and
\end{abstract}

S. D. Borgsteede $(\bowtie) \cdot$ I. L. Kok · J. C. Meeuse

T. P. G. M. de Vries · J. G. Hugtenburg

Department of Clinical Pharmacology and Pharmacy, VU

University Medical Center, De Boelelaan 1117, 1081HV

Amsterdam, The Netherlands

e-mail: s.borgsteede@gmail.com

S. D. Borgsteede

Kring Apotheek Boomstede, Gezondheidscentrum

Maarssenbroek, Maarssen, The Netherlands

M. J. Westerman

Department of Methodology and Statistics, Institute of Health

Sciences, Faculty of Earth and Life Sciences, VU University

Amsterdam, Amsterdam, The Netherlands
(4) routines in medication behaviour. Experience with medication and social support for medication behaviour were related to high levels of adherence in some patients, and to lower levels of adherence in others. Complicated medication regimens were mainly related to lower adherence, while social support and routines in medication behaviour were related to higher adherence. Conclusions Routines in medication behaviour were related to higher drug adherence. Patient education should not only address information about the disease and medication, but also more practical issues concerning drug intake. Hence, to improve drug adherence in patients with type 2 diabetes, pharmaceutical care might be aimed at the counselling of patients to organise drug use in their daily schedule.

Keywords Adherence $\cdot$ Drug use $\cdot$ Netherlands Patient education - Primary care - Qualitative research - Type 2 diabetes

\section{Impact of findings on practice}

- Practical information about how to fit drugs in daily routines could support patients in their adherence to medication.

- Factors such as information about medication and individual experiences with medication can be related to high as well as low adherence, hence interventions to improve adherence should be tailored to the individual patient.

- Positive and negative experiences of patients and his/ her relatives with medication can influence adherence to medication. Exploration of these experiences in counselling can give useful information to support adherence. 


\section{Introduction}

Adherence rates to drug regimens in patients with type 2 diabetes are relatively low, and vary widely between populations with adherence rates between 36 and 94\% [13]. Health care providers can motivate patients to be adherent, but the diabetes care has to be performed by the patient himself. Health care professionals have little direct control how patients manage their illness [4]. However, results of studies show growing evidence that patient outcomes are improved by changes in the process of care or by counselling the patient. To develop effective interventions and to train health care professionals to support patients, it is important to know which factors influence adherence with drug treatment [5].

Epidemiological studies have found many factors associated with drug adherence [6-9]. Reviews report that adherence has been associated with patient factors, social and medical support, and medication related aspects [1, 10]. Patient factors are for example the patient's age (older patients being more adherent), economic status (patients with a higher economic status being more adherent) and health beliefs (patients with beliefs about medicines as something harmful were less adherent) [1, 6, 11-13]. Social and medical support include among others family help and the patient-health care provider relationship, and patients with more support were more adherent. Medication related factors take into account the attitude towards medicines, the complexity of the medication regimen and the experience of side effects $[8,9,11]$. A positive attitude towards medicines, a less complex medication regimen and less experience of side effects were related to higher adherence rates. Studies that focussed on the patient's perspective and his experiences with drug adherence have been performed less frequently [14, 15].

Qualitative studies explored aspects that influenced the patient's opinion on several aspects of diabetes management [16-18]. These studies found that health beliefs, quality of the doctor/patient relationship, the course of diabetes and quality of information influenced drug adherence. Examples of these findings are that health beliefs could lead to reduced adherence due to lack of understanding of diabetes and its treatment. Also, health beliefs of patients could lead to adapt the recommended treatment and hence reduce adherence. Within the doctor/patient relationship patients perceived the doctor blaming the patient for negative health outcomes, and physicians not understanding the patient's difficulties as obstacles to adherence. With respect to information, lack of knowledge and conflicting information about the treatment could influence adherence negatively.

In order to develop interventions that improve diabetes care, the patient's perspective needs to be investigated further.

\section{Aim of the study}

The aim of the study was to explore both factors related to high and lower levels of adherence that patients experienced in their medication use, and to reflect upon the findings in the context of patient education and shared decision making.

\section{Method}

Study design

Qualitative, semi-structured interviews in patients with type 2 diabetes in primary care in the Netherlands.

Patient selection

Source population: patients were approached within the context of an educational epidemiological survey by health science students of the VU University Amsterdam. Fiftyfour family practices participated, and 60 students approached up to five patients in one practice. A total of 254 patients agreed to participate in a questionnaire study designed to study adherence among patients with type 2 diabetes [19]. Patients were from all over the Netherlands and were prescribed at least one oral anti-diabetic drug, were older than 40 years and their GP was (one of) the primary caregiver(s). All patients had adequate command of the Dutch language. The 173 (68\%) patients who were willing to participate in future research, were the source population for this qualitative study.

In the survey, adherence for each drug that was used was measured with the Medication Adherence Rating Scale (MARS-5) [20, 21]. The MARS is a questionnaire with five questions with for each question answer categories ranging from 1 (least adherent) to 5 (most adherent), so the higher scores suggest better adherence.

Study population: to include opinions of both adherent and less adherent patients, a theoretical sampling strategy was used [22]. Previous studies using the MARS-score to differentiate in high and lower adherence used different cut-off points [8, 23, 24]. As adherent patients we included 10 people with a maximum score of 25 on all drugs they used. As less adherent patients we approached the patients with the lowest MARS-score in our sample. These patients scored on at least one of their drugs a total MARS score below 21, and a score of 3 or less on at least two questions. We approached an equal number of adherent and less adherent patients to participate. Within this sample, we aimed to include a similar proportion of male and female patients, and patients from different age. Prior to the interview, each patient was contacted by phone: the 
investigators briefly described the aim of the patient interview, and sent an information sheet to the potential participant. The investigators (IK and JM) then made an appointment with the patient for the interview. Before the interview started the patients gave informed consent.

Interviews: semi-structured, in-depth interviews were performed in the patients' home. Patients were interviewed about their experiences with all drugs that were used and the factors related to high and lower levels of adherence they experienced. During the interview no reassessment of adherence with the MARS-questionnaire was performed. The interviews took 40-90 min and during the first four interviews we evaluated whether the topics in our guide were adequate to answer the research questions. In each interview open questions were formulated that covered general areas of interest as listed in the final topic guide (see Table 1). During the interviews, patients were asked to elaborate about these topics and to mention all subjects relevant from their own points of view. Partners or family members were not invited to participate, but if a partner of family member was present during an interview, their comments were welcomed and included in the data. The researchers assured that the information would remain confidential and that confidentiality was considered to their health care providers. All interviews were audio-taped, transcribed verbatim, and rendered anonymously. The investigators read the transcript while listening to an interview to ensure textual accuracy. The transcripts of the interviews then served as data.

The interviews were performed by two health sciences students (IK and JM). Prior to the interviews, both had followed an interview training, and during the entire

Table 1 Topics of the interview

How do patients use/organise their medication

Experiences with not taking medication

Reasons for non-adherence

Factors related to high levels of adherence for medication

Factors related to lower levels of adherence for medication

Checklist for possible factors related to high or lower levels of adherence for medication $^{\mathrm{a}}$

Forgetting

Social environment

Effect of medication

Side effects of medication

Information and knowledge about medication

Relation with general practitioner

Complexity of drug regimen

a After the first four interviews we noticed that patients found it difficult to describe factors related to high and lower levels of adherence spontaneously. After the open questions, we added a checklist that was used to trigger them to elaborate on possible factors related to adherence interview period they were supervised by experienced qualitative researchers (SB and MW).

\section{Analysis}

Background characteristics concerning age, gender, the number of medicines the patient used and how long they had been diagnosed with diabetes were derived from the database. The mean number of antidiabetic drugs per patient was calculated. Concomitant medication was classified according to ATC-codes [25]: cardiovascular medication (ATC-code C) was classified in cholesterol lowering drugs (ATC C10), and other cardiovascular drugs. Medication used for pain consisted of the combined classes M01 and N01. The number of patients with at least one drug in the six most frequently used ATC-classes other than antidiabetic drugs was presented. Also the mean number of drugs used by the patients within classes was calculated. All other drugs were categorized as 'other'.

All interview transcripts were analysed with support of QSR Nvivo 2.0, an established software package for ordering qualitative data. The first four interviews were transcribed and analysed directly after the interview to confirm the validity of the topic list. At the time ten interviews were carried out, certain themes began to be repeated (data saturation). The investigators coded these first ten transcripts independently to identify key themes, using the themes from the topic list (see Table 1) and themes that they considered to be important as codes. Citations from patients and partners covering these topics were included in the analysis. In the subsequent interviews these themes were further developed until additional interviews provided no new information with respect to the research question. During analysis, the authors ensured validity of the results by critical discussion and searching for cases which seemed to verify or to conflict with the insights derived from the interim analysis.

Ethical Approval: this study was exempt from review by the Medical Ethics Committee of the VU University Medical Center, as Dutch legislation does not request this for studies that do not affect the patient's integrity.

\section{Results}

Patient characteristics

Between April and June 2006, 22 patients were approached by the researchers. A total of 20 patients was included in the study. In three of the interviews, a partner (spouse) contributed to the interview, and their comments added information about the patient's thoughts and experiences. Table 2 summarizes the characteristics of the patients. Half 
Table 2 Characteristics of the interviewees $(\mathrm{n}=20)$

\begin{tabular}{lll}
\hline & Adherent $^{\mathrm{a}}$ & $\begin{array}{l}\text { Less } \\
\text { adherent }^{\mathrm{b}}\end{array}$ \\
\hline $\begin{array}{l}\text { Gender } \\
\text { Male }\end{array}$ & 5 & 5 \\
$\quad$ Female & 5 & 5 \\
Age, mean (range) & $68(52-85)$ & $72(62-92)$ \\
$\begin{array}{l}\text { Number of years diagnosed with diabetes } \\
\text { (range) }\end{array}$ & $6.0(2-16)$ & $4.5(1-10)$ \\
Total & 10 & 10 \\
\hline
\end{tabular}

$\overline{{ }^{a}}$ Adherent patients were defined as patients with a maximum MARSscore of 25 for all drugs they used

${ }^{\mathrm{b}}$ Less adherent patients were defined as patients who scored $\leq 3$ on at least 2 of the 5 questions of the MARS-questionnaire for at least one of the drugs they used

of the patients had a maximum MARS-score for adherence (adherent), and half of the patients scored three or lower on at least two of the five questions (less adherent). The mean age of the more and less adherent patients was comparable, and male and female patients were equally represented in both groups. Patients used comparable medication for concomitant diseases: most patients used cardiovascular medication to control blood pressure, and cholesterol lowering drugs (Table 3). Other frequently used drugs in both groups were drugs for other chronic diseases: alimentary tract/metabolism, blood and blood forming organs (anti-coagulants), analgesics and respiratory drugs.

Aspects emerging from the analysis

Four aspects that influenced adherence to medication emerged from the interviews: (1) information about the prescribed medication, (2) experience with medication and complications with using medication, (3) support for medication behaviour and (4) routines in medication behaviour. Information, experience with medication, and support for medication behaviour were related to high adherence in some patients, while the same aspects were related to lower adherence in others. If patients experienced their medication complicated to use, this was related to lower levels of adherence. Routines in medication behaviour were associated with high adherence. The factors related to high and lower levels of adherence were expressed by adherent as well as less adherent patients, and we found no indication for differences between male and female patients nor different factors raised by younger and elderly patients. Most patients found it difficult to describe factors related to high and lower levels of adherence spontaneously, however they were triggered by the items we used on the checklist. The citations shown exemplify the opinions of the patients.

Information about the medication

Information and knowledge about medication emerged as one of the aspects related to adherence in both more and less adherent patients, however we did not measure knowledge with a questionnaire. When patients spoke about information they sometimes spoke about (lack of) knowledge as the possible result of having (in)sufficient information. Patients distinguished different sources of information about medication. Verbal instructions by the prescriber were mentioned, and also written and oral information by the pharmacy, and the package leaflet of the specific drug. This is illustrated by the following patients who summarized some of these sources:

Table 3 Drugs used by the interviewees $(n=20)$

\begin{tabular}{|c|c|c|c|c|}
\hline \multirow[b]{2}{*}{ ATC-class of drugs (ATC) } & \multicolumn{2}{|c|}{ Adherent $^{\mathrm{a}}$} & \multicolumn{2}{|c|}{ Less adherent $^{\mathrm{b}}$} \\
\hline & $\begin{array}{l}\text { Patients } \\
\text { (n) }\end{array}$ & $\begin{array}{l}\text { Drugs per patient }{ }^{\mathrm{c}} \text { (mean, } \\
\text { range) }\end{array}$ & $\begin{array}{l}\text { Patients } \\
\text { (n) }\end{array}$ & $\begin{array}{l}\text { Drugs per patient }{ }^{\mathrm{c}} \text { (mean, } \\
\text { range) }\end{array}$ \\
\hline Antidiabetic drugs $(\mathrm{ATC}=\mathrm{A} 10)$ & 10 & $1.6(1-2)$ & 10 & $1.3(1-2)$ \\
\hline $\begin{array}{l}\text { Alimentary tract and metabolism }(\mathrm{ATC}=\mathrm{A} \text {, without } \\
\text { antidiabetic drugs) }\end{array}$ & 5 & $1(1)$ & 6 & $1.2(1-2)$ \\
\hline Blood and blood forming organs (ATC B) & 4 & $1.3(1-2)$ & 3 & $2(1-3)$ \\
\hline Cholesterol lowering drugs $(\mathrm{ATC}=\mathrm{C} 10)$ & 7 & $1(1)$ & 5 & $1(1)$ \\
\hline Cardiovascular system $(\mathrm{ATC}=\mathrm{C}$, all other) & 9 & $2.7(1-5)$ & 7 & $1.9(1-3)$ \\
\hline Analgesics (ATC = M01, N01) & 2 & $1(1)$ & 3 & $2(1-3)$ \\
\hline Respiratory system (ATC = R) & 2 & $1(1)$ & 3 & $3(1)$ \\
\hline Other & 5 & $1.8(1-3)$ & 7 & $1.9(1-4)$ \\
\hline Total & 10 & $7.0(4-10)$ & 10 & $6.6(4-10)$ \\
\hline
\end{tabular}

a Adherent patients were defined as patients with a maximum MARS-score of 25 for all drugs they used

${ }^{\mathrm{b}}$ Less adherent patients were defined as patients who scored $\leq 3$ on at least 2 of the 5 questions of the MARS-questionnaire for at least one of the drugs they used

${ }^{c}$ Mean number of drugs per patient that used at least one drug within this category 
"Well, it [knowledge about medicines] is important as it concerns the doctor's advice how to take medicines. You follow his advice... and you read the package leaflet. The pharmacy provides those big information sheets, with everything written clearly. Well you read everything..." (Woman, 62 years, less adherent)

Knowledge about medication was for many patients rather limited, however lack of information was not always considered a limiting factor for adherence by the patients themselves:

Knowledge about medication? I have no idea! I Medicines are prescribed, I use them. That's it. I never read the package leaflet. When you read it, you lose courage to use them any longer, and in my opinion you have to use them... the colours tell me how: blue is for the prostate, and I have orange and white, and for my sugar I use a tablet somewhat larger. I also have another one for my stomach. (male, 71 years, less adherent)

For some patients however, information about the medication and the underlying disease was important and associated with the intention to comply to their medication regimen:

It [my diabetes related medication] has been explained very well. This disease may damage your veins, your eyes, and even more. It will destroy you: that was explained perfectly. For me it was clear, hence I use my medicines and understand their importance. (male, 52 years, adherent)

Experience with medication and complications with usage

Patients' experiences with medicines influenced their attitude and this was related to their level of adherence. Direct influences were the effects that patients experienced when they omitted medication, such as pain or heart burn. To prevent these reactions they complied to their regimen. When patients experienced side effects, some patients stopped their medication:

If I experience side effects, 1 stop taking medicines. I don't feel well. And then, my doctor thinks: what to do next? Usually he prescribes me another drug. (female, 72 years, adherent)

Not only current, but patients' past experiences with health care affected their adherence. Moreover, experiences of close friends and family members with medication could lead to beliefs in the necessity of treatment that influenced drug adherence. An example was a patient who was motivated to comply with her medication regimen because she had seen the complications of diabetes in her family:

I had a sister in law, she died recently. It started with losing a toe, then the top of her foot, later her leg till under her knee, and finally she lost her whole leg. Well, now she does not live any more. That frightens me very much. (female, 65, adherent)

For most patients, using medication in daily practice was complicated. Patients distinguished two aspects: complexity because they had to take medication at different times a day, and complexity in taking the right amount of medication because they had to take more than one drug, or had to perform difficult actions before they could take the drug. Another aspect of the complexity of taking medicines at different times was that this was (more) difficult to schedule. This was problematic for a patient who had to combine oral anti-diabetics with insulin:

A tablet is easier to take, it doesn't matter when you take it half an hour earlier or later. But when you inject insulin, it has to be at the right time. You must inject and eat directly. (woman, 65, adherent)

Taking the right amount was sometimes complex when patients had to split the tablets themselves, because they had to take another amount than one (whole) tablet.

When you split them [the tablets]-and that is strange-1 day you have three quarters of a tablet and the other day you only have one quarter. You have to cut them on the line of fracture. And I have to use them, you can't throw it away! (male, 72 years, adherent)

Many patients had experienced a situation in which it was difficult to take all the medication, because of the quantity or because of size. Only in one case it was mentioned this was actually a factor that limited adherence:

Well he [my husband] says: "that one I won't take today. That's such a big one, he will stuck in my throat, and then my throat will be burning." (partner of patient, 71 years, female, less adherent)

Social support for medication behaviour

We used Dalgard's conceptualization of social support as 'help in difficult life situations' [26]. Patients experienced support for their medication behaviour by both their social environment and health care professionals. Most patients trusted their treating physician(s), although this was not always related to improved adherence of these patients. 
The next thoughts are from a patient who trusted his physician, and who did not discuss his medication with his physician:

"My point of view is that these people (physicians) have studied, and have proven they can do something in our society. You surrender to them. When he prescribes, who am I to ask: 'does that drug do anything?' In the end, I am a layman." (male, 76 years, less adherent)

However, not every patient had such an opinion of his/her physician, in one extreme case a patient experienced lack of support and this resulted in an repulsive attitude of the patient to her physician:

Well, my GP and I, we don't like each other. We have had a conflict several times. He can say to me "you should do this or that", but I will not listen to him! (female, 71 years, less adherent)

Most patients considered their medication their individual responsibility, and help of their partner or children was not needed. For them, support from their social environment was not an issue. Others needed help for practical reasons such as a bad visibility or not being able to get tablets out of the blisters. Also, six patients (five of them males) appreciated help by partners or children, sometimes indolence was the main reason:

Well, I can manage it myself [my medication], but it is very easy when she [his wife] thinks about it! (male, 67 years, adherent)

\section{Routines in medication behaviour}

Many factors that influenced adherence had to do with the daily routine of taking medication. Disturbances in this routine were related to less adherence, such as not thinking about the medication because of stress and being busy:

Once in a while you forget [taking your medicines], in certain situations, when you are not at home. You don't think about the possibility you won't be at home in advance. (female, 75 years, less adherent)

Routines in taking medication were experienced as factors related to higher levels of adherence. Many patients had developed certain habits that were a safeguard to remember their times of intake. Patients were creative in these drug plans:

Well, we put the medicines near the breakfast plates, in sight. So it's easy to keep in mind In the morning you open the kitchen cupboard and then you remember. (male, 67 years, adherent)
Another way to fit medication use in the daily regimen was to attune times of intake with common patterns. Daily routines and regularity were related with higher adherence, also in the next patient who was less adherent when she deviated from her daily routines:

Well, sometimes I forget the drugs to control my sugar. When I am somewhere else it happens that I think: "Oops, I have forgotten my medicines." ...This is what I'm used to do [when I am at home]: get up, go to the bathroom, and take my medicines. It's quite a ritual, honestly. (female, 72 years, less adherent)

\section{Discussion}

We found comparable aspects that were related to adherence in adherent and less adherent patients. Patients identified four aspects related to adherence to medication: (1) information about the prescribed medication, (2) experience with medication and complications with using medication, (3) social support for medication behaviour and (4) routines in medication behaviour. Experience with medication and social support for medication behaviour were related to high levels of adherence in some patients, and to lower levels of adherence in others. Complications with medication usage were related to lower levels of adherence, and both information about medication and routines were factors related to high levels of adherence.

This study confirms previous findings in the literature. Information, experience with medication and complications with use, social support and routines in medication behaviour have been found in other qualitative and quantitative studies as factors influencing drug adherence, however mostly they were identified separately $[1,5,16$, $17,27,28]$. In this study, these aspects were identified together, in both adherent and less adherent patients. This suggest that these factors are the same for adherent and less adherent patients, and that patients with good and poor control of diabetes identify the same types of problems in managing their disease [29].

In diabetes, barriers to adherence were related to qualitative factors as health beliefs, context and relationships [18]. We found factors as earlier experiences with medication and social support to be related to both lower and high adherence. Earlier experiences could be related to less adherence in some patients, for example when they experience side effects. Other patients had family members with severe complications, and these experiences were related to higher adherence. Because qualitative analysis explores concepts such as health beliefs in all their complexity, a relationship described by one patient is different as a 
relationship described by another. This might explain why for chronic treatment no simple intervention to enhance adherence to medication was effective [11]. Only some studies that investigated complex interventions that combined different strategies led to (small) improvements in adherence [11].

Our study adds to existing literature that adherence is not only related to the patient's experience with current medication, but also to experiences with the disease, with medication in the past, and experiences of people within close relationship to the patient. These experiences influence the patient's attitude towards diabetes medicines, as well as the opinion of the treating physician [30].

Lack of routines could hamper drug adherence, but habitational behaviour was mentioned to favour adherence. A factor that emerged in this study were routines in drug behaviour. In studies that investigated drug behaviour of HIV-positive drug users, structured life and routines were found important factors related to adherence [31]. A review of interventions by pharmacists showed that a system of reminders improved medication adherence [32], and a recent study demonstrated that routines were important for drug adherence in elderly [33].

Although the results from our study are too limited to develop a theoretical framework on its own, we discuss how our findings might fit within the Common Sense Model (CSM) [34]. According to the CSM, cognitive and emotional processes operate independently, and this model proposes three stages that regulate behaviour: (1) representation of the illness (IR), (2) the patient's coping strategy and (3) the appraisal stage in which coping and progress are assessed.

We can consider opinions about adherence towards medication as one of the domains of the IR of diabetes. Our results show that the patient's current and past experiences with the disease, and experiences of people within close relationship of the patient were related to high or lower levels of adherence. Within the CSM this can be interpreted as coping strategies that can influence the IR of the patient. In a similar way, social support can be interpreted as coping strategy by adding information to the patient's beliefs. The development of routines can be seen as a coping strategy how to organise medication behaviour. The goal of this behaviour is that the potential danger is regulated.

It has been proven difficult to develop interventions that improve adherence. [11, 35] Probably, different factors are relevant for different patients and tailored individualised strategies are needed $[36,37]$. With respect to information about medication, knowledge, and social support intervention strategies show limited success [11]. Interventions that were effective were complex, and combining interventions in drug adherence with other lifestyle interventions such as diet and physical activity might be more effective, as patients find undertaking multiple lifestyle changes at the same time helpful [38].

Dependent upon the underlying cause for not taking medication, supporting routines in medication behaviour might be promising to investigate further when developing new intervention strategies to improve adherence [39]. Routines do not require conscious deliberation of health choices, and they may avoid unpleasant thoughts about the disease. A review of pharmacist's interventions to enhance diabetes adherence found five studies that described an intervention, of which the one that stimulated routines was the only one that improved adherence clearly [32]. To increase medication adherence in patients with diabetes type 2 , interventions that stimulate routines in medication behaviour might be developed.

Obviously, our study has certain limitations. A first limitation of this study was that a limited number of patients were interviewed, and these patients participated in an earlier study about drug use and adherence. We identified less adherent patients by self report. It is likely that the type of patients that admit being less adherent differ from the patients that are less adherent, but report themselves to be adherent. We divided patients in more and less adherent according to their MARS-score. The MARSquestionnaire has not been developed to provide a cut-off for adherent and less adherent patients, and also the MARS-score might not agree with real adherence [8]. Moreover, adherence is not a static state of being, and actual adherence for patients in both groups may have varied across the study period.

A second limitation was that the presence of family members influenced the interview. Although this might also limit the free expression of thought and lead to social desirable answers, we believe in this setting the contribution of a spouse led to more detailed information about the patient's thoughts and experiences.

Strengths of this study were that the researchers were not involved in the process of diabetes care themselves. To reduce interviewer bias two researchers interviewed patients using the same topic guide.

\section{Conclusion}

Information about medication, experience with medication and complications with using medication, support for medication behaviour and routines in medication behaviour were factors related to drug adherence. Routines in medication behaviour were related to high drug adherence. Patient education should not only address knowledge about the disease and medication, but also more practical issues concerning drug taking. Hence, to improve drug adherence 
in patients with type 2 diabetes, pharmaceutical care might be aimed at the counselling of patients to organise drug use in their daily schedule.

Acknowledgments We wish to thank all patients, their family members and the general practitioners for their contribution to this study.

\section{Funding None.}

Conflicts of interest None declared.

Open Access This article is distributed under the terms of the Creative Commons Attribution Noncommercial License which permits any noncommercial use, distribution, and reproduction in any medium, provided the original author(s) and source are credited.

\section{References}

1. Sabaté E. Adherence to long-term therapies. In: WHO, editor. 2003. Geneva: WHO.

2. Cramer JA. A systematic review of adherence with medications for diabetes. Diabetes Care. 2004;27(5):1218-24.

3. Morris LS, Schulz RM. Patient compliance-an overview. J Clin Pharm Ther. 1992;17(5):283-95.

4. Funnell MM, Anderson RM. MSJAMA: the problem with compliance in diabetes. JAMA. 2000;284(13):1709.

5. Brown JB, Harris SB, Webster-Bogaert S, Wetmore S, Faulds C, Stewart M. The role of patient, physician and systemic factors in the management of type 2 diabetes mellitus. Fam Pract. 2002;19(4):344-9.

6. Walker EA, Molitch M, Kramer MK, Kahn S, Ma Y, Edelstein S, et al. Adherence to preventive medications: predictors and outcomes in the diabetes prevention program. Diabetes Care. 2006;29(9):1997-2002.

7. Pedan A, Varasteh L, Schneeweiss S. Analysis of factors associated with statin adherence in a hierarchical model considering physician, pharmacy, patient, and prescription characteristics. J Manag Care Pharm. 2007;13(6):487-96.

8. Mardby AC, Akerlind I, Jorgensen T. Beliefs about medicines and self-reported adherence among pharmacy clients. Patient Educ Couns. 2007;69(1-3):158-64.

9. Grant RW, Devita NG, Singer DE, Meigs JB. Polypharmacy and medication adherence in patients with type 2 diabetes. Diabetes Care. 2003;26(5):1408-12.

10. Vermeire E, Wens J, Van Royen P, Biot Y, Hearnshaw H, Lindenmeyer A. Interventions for improving adherence to treatment recommendations in people with type 2 diabetes mellitus. Cochrane Database Syst Rev. 2005;(2):CD003638.

11. Haynes RB, Ackloo E, Sahota N, McDonald HP, Yao X. Interventions for enhancing medication adherence. Cochrane Database Syst Rev. 2008;(2):CD000011.

12. Nurymberg K, Kreitler S, Weissler K. The cognitive orientation of compliance in short- and long-term type 2 diabetic patients. Patient Educ Couns. 1996;29(1):25-39.

13. Rubin RR. Adherence to pharmacologic therapy in patients with type 2 diabetes mellitus. Am J Med. 2005;118(Suppl 5A):27S$34 \mathrm{~S}$.

14. Morris LS, Schulz RM. Medication compliance: the patient's perspective. Clin Ther. 1993;15(3):593-606.

15. Grol R, Wensing M, Mainz J, Ferreira P, Hearnshaw H, Hjortdahl $\mathrm{P}$, et al. Patients' priorities with respect to general practice care: an international comparison. European task force on patient evaluations of general practice (EUROPEP). Fam Pract. 1999;16(1):4-11.

16. Vinter-Repalust N, Petricek G, Katic M. Obstacles which patients with type 2 diabetes meet while adhering to the therapeutic regimen in everyday life: qualitative study. Croat Med J. 2004;45(5):630-6.

17. Vermeire E, Van Royen P, Wens J, Denekens J. The adherence of type 2 diabetes patients to their therapeutic regimens: a qualitative study from the patient's perspective. Pract Diabetes Int. 2003;20(6):209-14.

18. Vermeire E, Hearnshaw H, Ratsep A, Levasseur G, Petek D, van Dam H, et al. Obstacles to adherence in living with type-2 diabetes: an international qualitative study using meta-ethnography (EUROBSTACLE). Prim Care Diabetes. 2007;1(1):25-33.

19. Samadhan A, Meeuse JC, Derraz S, Dusseljee T, Oirbans T, Borgsteede $S$, et al. Adherence to different drugs in patients with type II diabetes (abstract). Br J Clin Pharmacol. 2006;62(6):731.

20. Horne R, Weinman J, Hankins M. The beliefs about medicines questionnaire: the development and evaluation of a new method for assessing the cognitive representation of medication. Psychol Health. 1999;14:1-24.

21. Fialko L, Garety PA, Kuipers E, Dunn G, Bebbington PE, Fowler $\mathrm{D}$, et al. A large-scale validation study of the medication adherence rating scale (MARS). Schizophr Res. 2008;100(1-3):53-9.

22. Mason J. Qualitative researching. 2nd ed. London: Sage Publications; 2002.

23. Bowskill R, Clatworthy J, Parham R, Rank T, Horne R. Patients' perceptions of information received about medication prescribed for bipolar disorder: implications for informed choice. J Affect Disord. 2007;100(1-3):253-7.

24. George J, Kong DC, Thoman R, Stewart K. Factors associated with medication nonadherence in patients with COPD. Chest. 2005;128(5):3198-204.

25. WHO Collaborating Centre for Drug Statistics Methodology. ATC index with DDDs. Oslo: WHO; 2003.

26. Dalgard OS. Social support-Definition and scope. http://www. euphix.org EUphactlDeterminants of health|Environment $\backslash$ Social support (2009). Cited 4 Jan 2011.

27. Veazie PJ, Cai S. A connection between medication adherence, patient sense of uniqueness, and the personalization of information. Med Hypotheses. 2007;68(2):335-42.

28. Ryan GW, Wagner GJ. Pill taking 'routinization': a critical factor to understanding episodic medication adherence. AIDS Care. 2003;15(6):795-806.

29. Hill-Briggs F, Cooper DC, Loman K, Brancati FL, Cooper LA. A qualitative study of problem solving and diabetes control in type 2 diabetes self-management. Diabetes Educ. 2003;29(6):1018-28.

30. Anderson RM, Funnell MM. Compliance and adherence are dysfunctional concepts in diabetes care. Diabetes Educ. 2000; 26(4):597-604.

31. Wagner GJ, Ryan GW. Relationship between routinization of daily behaviors and medication adherence in HIV-positive drug users. AIDS Patient Care STDS. 2004;18(7):385-93.

32. Lindenmeyer A, Hearnshaw H, Vermeire E, Van Royen P, Wens $\mathrm{J}$, Biot Y. Interventions to improve adherence to medication in people with type 2 diabetes mellitus: a review of the literature on the role of pharmacists. J Clin Pharm Ther. 2006;31(5):409-19.

33. Tordoff J, Simonsen K, Thomson WM, Norris PT. "It's just routine." A qualitative study of medicine-taking amongst older people in New Zealand. Pharm World Sci. 2010;32(2):154-61.

34. Harvey JN, Lawson VL. The importance of health belief models in determining self-care behaviour in diabetes. Diabetic Med. 2009;26(1):5-13.

35. Wens J, Vermeire E, Hearnshaw H, Lindenmeyer A, Biot Y, Van Royen P. Educational interventions aiming at improving 
adherence to treatment recommendations in type 2 diabetes: a sub-analysis of a systematic review of randomised controlled trials. Diabetes Res Clin Pract. 2008;79(3):377-88.

36. Thorne S, Paterson B, Russell C. The structure of everyday selfcare decision making in chronic illness. Qual Health Res. 2003;13(10):1337-52.

37. Velligan DI, Wang M, Diamond P, Glahn DC, Castillo D, Bendle $\mathrm{S}$, et al. Relationships among subjective and objective measures of adherence to oral antipsychotic medications. Psychiatr Serv. 2007;58(9):1187-92.

38. Malpass A, Andrews R, Turner KM. Patients with Type 2 Diabetes experiences of making multiple lifestyle changes: a qualitative study. Patient Educ Couns. 2009;74(2):258-63.

39. Reach G. Role of habit in adherence to medical treatment. Diabetic Med. 2005;22(4):415-20. 